\title{
СИНТЕЗ АНАЛОГОВ ИВАНЮКИТА-Na-Т И ИВАНЮКИТА-Na-C ИЗ СЫРЬЯ КОЛЬСКОГО ПОЛУОСТРОВА
}

\author{
Яничева Н.Ю., Селиванова Е.А. ${ }^{2}$, Пахомовский Я.А. ${ }^{2}$, Иванюк Г.Ю. ${ }^{2}$, Николаев А.И. ${ }^{3}$, \\ Яковенчук В.Н. ${ }^{2}$ \\ ${ }^{1}$ Центр наноматериаловедения КНЦ РАН, Anamumbl, mage13@bk.ru \\ ${ }^{2}$ Геологический институт КНЦ РАН, Апатиты \\ ${ }^{3}$ Институт химии и технологии редких элементов и минерального сырья им. И.В. Тананаева КНЦ \\ PAH, Anamumbl
}

Титаносиликаты группы иванюкита и их синтетические аналоги (SIV) являются высокоэффективными ионообменными материалами, способными включать в свою структуру одно-, двух- и трехвалентные катионы металлов, включая ${ }^{137} \mathrm{Cs}$ и ${ }^{90} \mathrm{Sr}$ и могут быть использованы в качестве сорбентов данных радионуклидов из растворов сложного солевого состава с последующим получением устойчивой титанатной керамики $[1,7,9]$ namely, layered hydrazinium titanate LHT-9, (N 2 H 5.Taким образом, актуальная проблема переработки жидких радиоактивных отходов (ЖРО), накопленных на предприятиях атомной энергетики и военно-промышленного комплекса, может быть решена с помощью синтетических аналогов иванюкита, получение которых возможно из сырья и отходов горнодобывающих предприятий Мурманской области. Впервые синтез иванюкитоподобного титаносиликата тригональной модификации, $\mathrm{Na}_{4}\left[(\mathrm{TiO})_{4}\left(\mathrm{SiO}_{4}\right)_{3}\right] \cdot 6 \mathrm{H}_{2} \mathrm{O}$, был осуществлен из раствоpa $\mathrm{Na}_{4} \mathrm{TiO}_{6}$, смешанного с силикатом натрия [8]. В 2012 г. в ИХТРЭМС КНЦ РАН был разработан способ гидротермального синтеза SIV на основе сульфата титанила и аммония, получаемого при сернокислотной переработке апатит-титанит-нефелиновых руд хибинских месторождений [2]. Целью настоящей работы являлась разработка технологии синтеза аналогов иванюкита-Na-T (SIV-T) и иванюкита-Na-C (SIV-C) гидротермальным способом с использованием в качестве исходных компонентов недорогих реагентов и прекурсоров на основе минерального сырья Кольского полуострова.

\section{Материалы и методы исследования}

В качестве прекурсоров для синтеза SIV использовали четыреххлористый титан $\mathrm{TiCl}_{4}$ (о.с.ч., ТУ 6-09-2118-77), производимый по хлорной технологии из лопарита [3] на Соликамском магниевом заводе (АО «СМЗ», г. Соликамск). В качестве реагентов использовали: гидроксид калия (Fisher Chemical), гидроксид натрия (ч.д.а.), пероксид водорода (осч 8-4), силикат натрия 5-водн. (имп.).

Синтез SIV осуществлён в 0.04-7.5 литровых автоклавах фирмы Parr Instrument и собственного производства (ЦНМ КНЦ РАН, ИХТРЭМС КНЦ РАН). Синтетические образцы изучены методами рентгенофазового анализа (УРС-1, ГИ КНЦ РАН; Bruker D2 Phaser, СПбГУ), сканирующей электронной микроскопии (Leo-1450/Quantax, ГИ КНЦ РАН), анализа поверхности (TriStar II 3020). При обработке дифрактограмм применяли компьютерную программу OriginPro 8.0.

\section{Методика эксперимента}

Синтез осуществляли с использованием хлоридного раствора пероксокомплексов Ti(IV), полученного добавлением $\mathrm{TiCl}_{4}$ к раствору пероксида водорода [5]. В качестве кремнийсодержащего реагента был использован коллективный раствор силиката натрия и гидроксидов натрия и калия. Смешение реагентов осуществлялось посредством приливания титансодержащего раствора к кремнийсодержащему при непрерывном перемешивании. Далее производилась выдержка полученной титанокремниевой композиции в автоклаве без перемешивания при температуре $160^{\circ} \mathrm{C}$ и давлении, соответствующем давлению насыщенных паров воды при данной температуре, в течение заданного времени. Объём автоклавов составлял от 0.04 до 7.5 л, степень заполнения - 50-70\%. Образовавшуюся твердую фазу отделяли от раствора фильтрованием под вакуумом, промывали 5-кратным объёмом дистиллированной воды и высушивали при температуре $65^{\circ} \mathrm{C}$. Состав конечного титаносиликатного продукта определяется исходным соотношением компонентов, а также температурой (ав- 


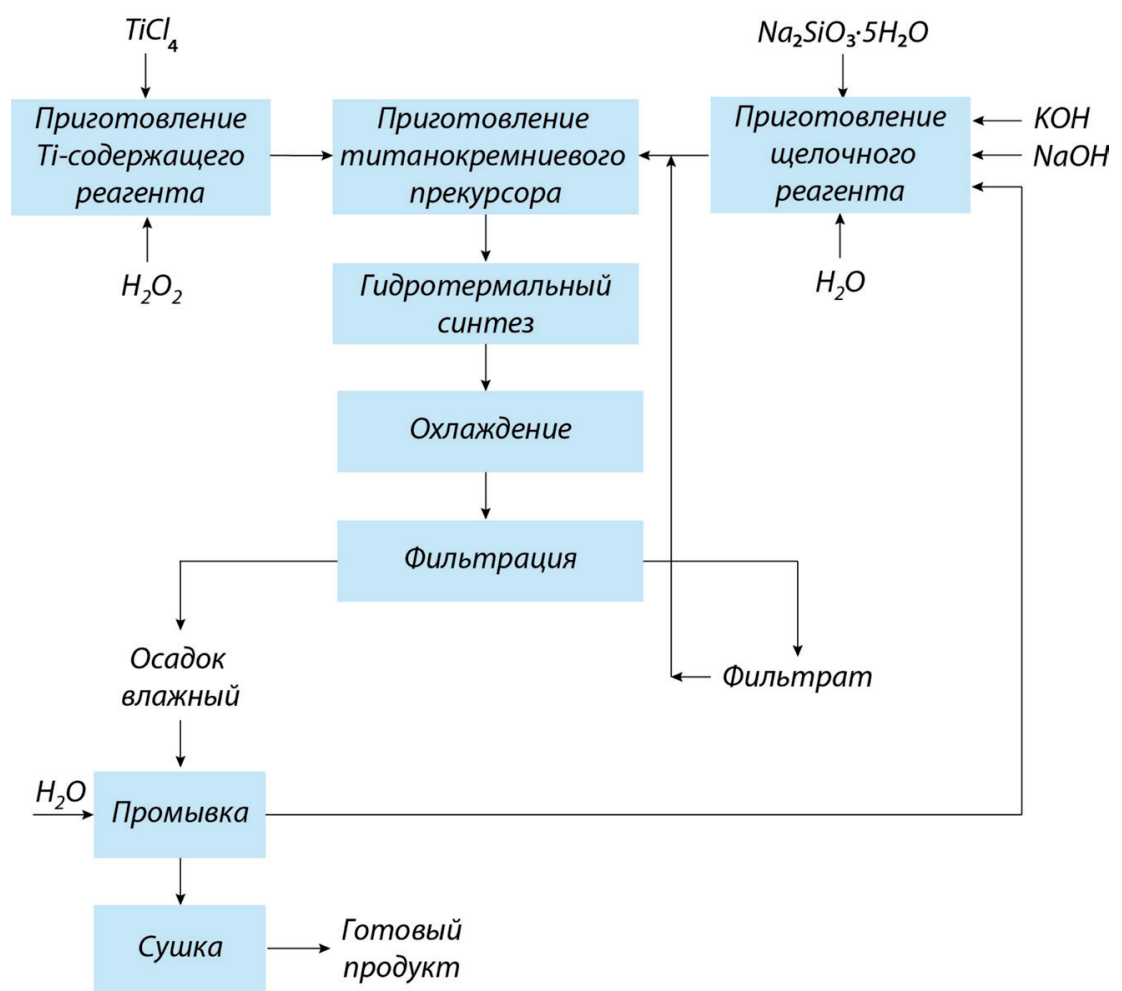

Рис. 1. Принципиальная технологическая схема получения SIV на основе продуктов хлорной переработки ловозёрского лопарита $\left(\mathrm{TiCl}_{4}\right)$.

тогенным давлением) и кинетикой гидротермального синтеза. Разработанная в ходе данного исследования технологическая схема синтеза SIV из сырья Мурманской области представлена на рис. 1.

\section{Результаты}

В ходе проведенного исследования SIV-T и SIV-C были получены в виде белых кристаллических порошков, в которых размер отдельных частиц составляет несколько микрон. Установлено, что данные соединения могут представлять собой продукты различной морфологической формы (рис. 2). На рис. 2 видно, что SIV может быть образованы плоскими частицами размером до 2 мкм, срастающимися в агломераты (морфологический тип D - dust-like , рис. 2 a, б), а также крупными агрегатами (морфологический тип P - porcelain-like, рис. 2 в, г), состоящими из плоских частиц размером меньше 150 нм, размер таких агрегатов может составлять более 1 см [7]. При этом SIV ладает более развитой поверхностью и вдвое большим диаметром макропор, его поровая система является однородной и преимущественно представлена крупными мезопорами, что обусловливает лучшую кинетику сорбции различных катионов именно на $\mathrm{SIV}_{\mathrm{p}}$, достаточно прочные агрегаты которого, возможно, могут быть использованы в динамическом режиме сорбции без предварительного гранулирования.

Рентгеноструктурное изучение продуктов, полученных в ходе гидротермального синтеза SIV-C из одной и той же исходной композиции в течение 1-36 ч, показало, что хорошо раскристаллизованный SIV-C формируется за 12 и более часов (продукты 1-5, рис. 3). При меньшем времени синтеза значительная часть титана ещё находится в составе (полу)аморфных продуктов, а более длительная выдержка SIV-C в автоклаве его структурного состояния существенно не изменяет.

Важно отметить, что соотношение между $\mathrm{Na}, \mathrm{K}$ и $\mathrm{Si}$ в составе раствора, оставшегося после первого синтеза, полностью удовлетворяет условию проведения следующего синтеза SIV-T и SIV-C с добавлением только титановой составляющей. Нами установлено, что возможно, по крайней мере, двухразовое повторное использование остаточного Na-K-Si-раствора без существенного изменения качества получаемых соединений. Кроме того, подобно своим природным аналогам [6], SIV-T 

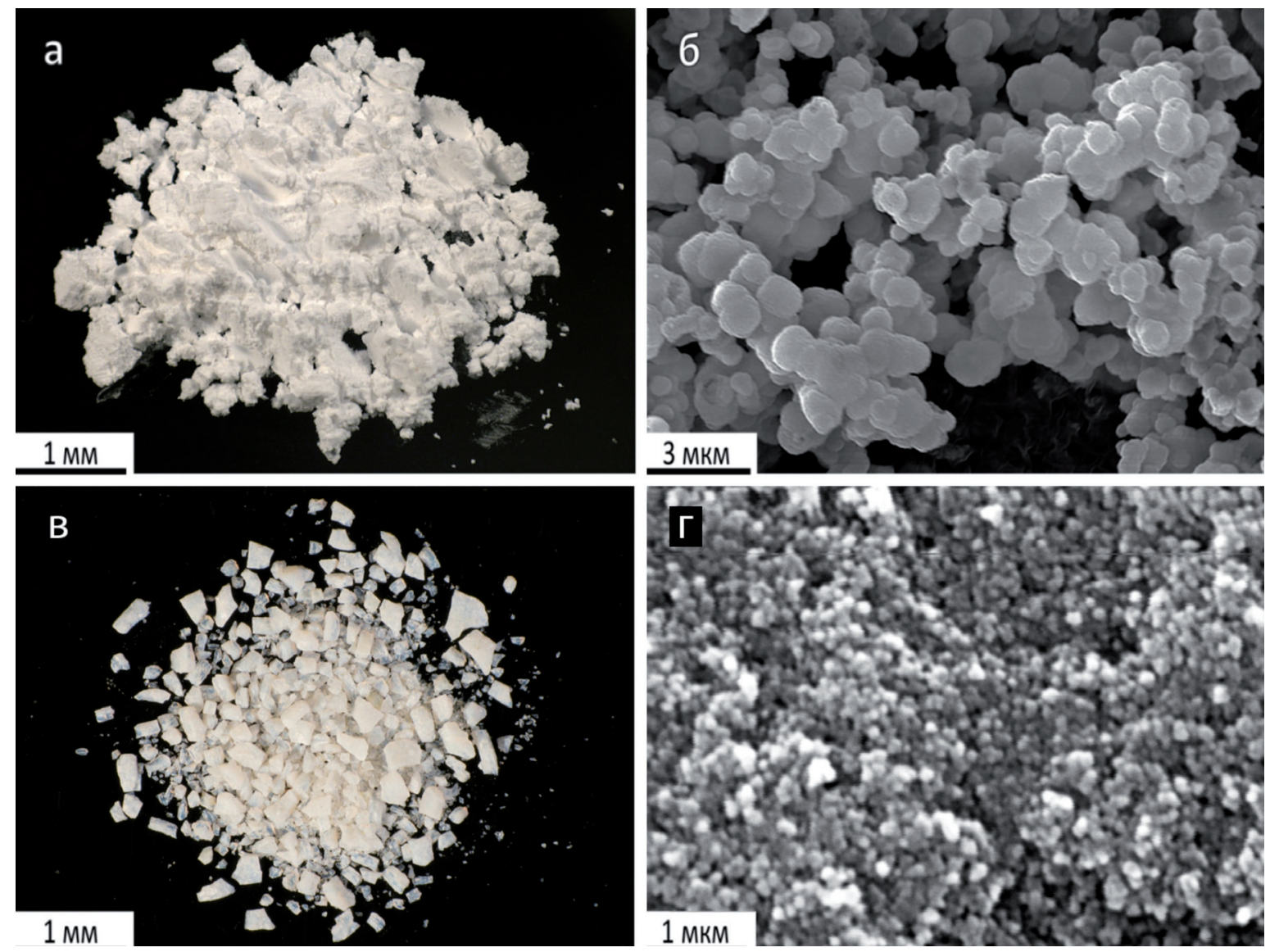

Рис. 2. Внешний вид $\operatorname{SIV}_{D}$ (a) и $\operatorname{SIV}_{P}$ (в) и увеличенное изображение частиц, их слагающих, во вторичных электронах (б и г соответственно) [7].

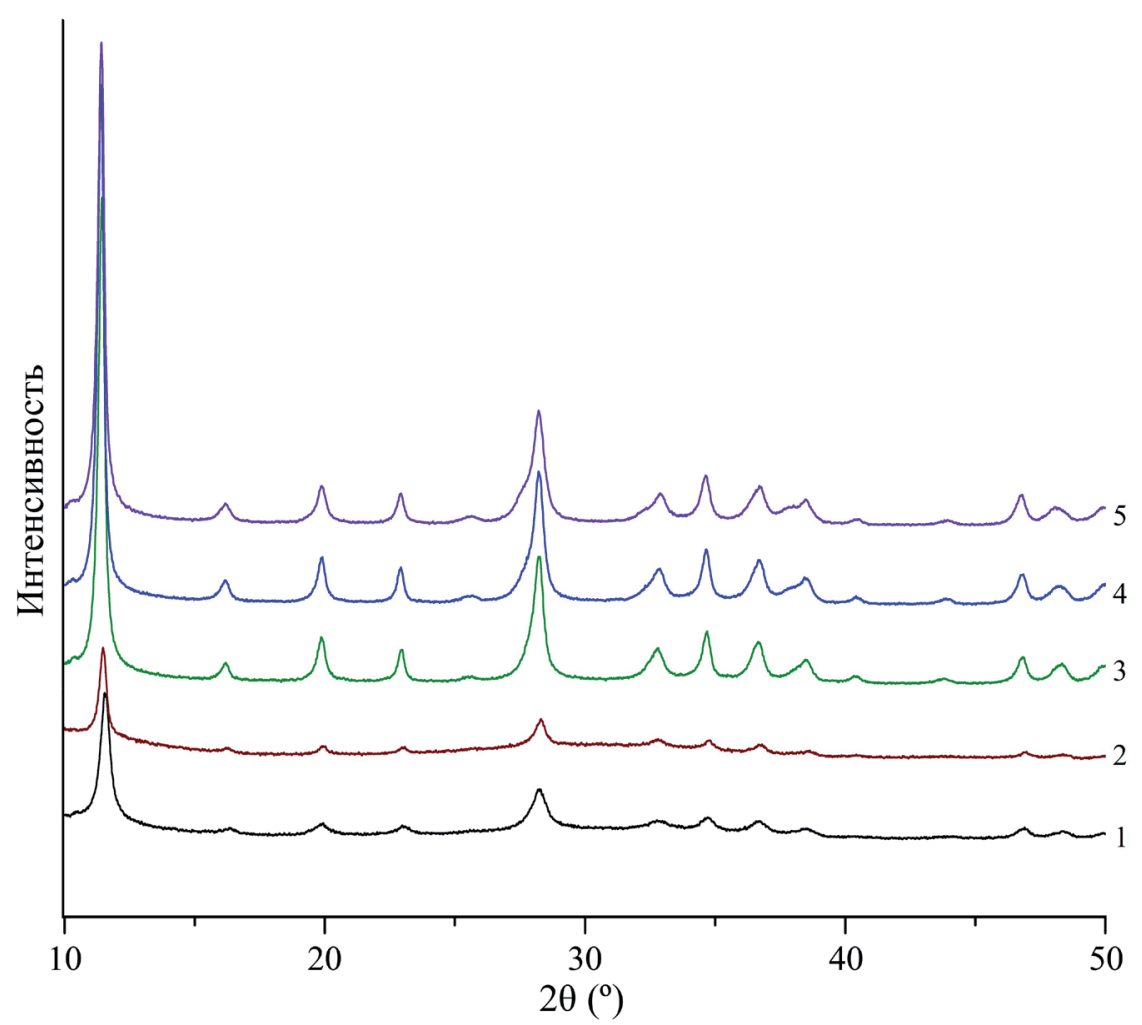

Рис. 3. Дифрактограммы SIV-C, синтезированного за 3 (1), 6 (2), 12 (3), 24 (4) и 36 часов (5). 
и SIV-C обратимо трансформируются друг в друга при (де)протонировании без изменения обменных свойств. Стоит также отметить, что получение SIV-T возможно с использованием меньшего количества воды (по сравнению с SIV-C), и сопровождается образованием более концентрированного фильтрата, что необходимо для обеспечения более эффективного его использования в обороте с доукреплением только титансодержащим реагентом. Таким образом, технологию производства SIV целесообразно организовать на основе получения SIV-T.

\section{Благодарности}

Авторы выражают глубокую благодарность д.т.н. Л.Г. Герасимовой, д.т.н. М.В. Масловой (ИХТРЭМС КНЦ РАН) за ценные рекомендации по вопросам синтеза титаносиликатов и обсуждение полученных результатов, к.т.н. И.Р. Елизаровой, А.И. Князевой, В.Н. Коровину (ИХТРЭМС КНЦ РАН), к.г.-м.н. Е.С. Житовой (СПбГУ) за помощь в исследованиях. Исследования проводились при финансовой поддержке программы Фонда содействия развитию малых форм предприятий в научно-технической сфере.

\section{Литература}

1. Бритвин С.Н. Применение титансодержащих сорбентов для очистки жидких радиоактивных отходов с последующей консервацией радионуклидов в титанатных керамиках типа SYNROC / C.Н. Бритвин, Л.Г. Герасимова, Г.Ю. Иванюк [и др.] // Химическая технология. 2015. № 4. С. 229-238.

2. Пат. 2467953 Российская Федерация, МПК C01G 23/00, С22B 3/08. Способ переработки титансодержащего концентрата / Л.Г. Герасимова, А.И. Николаев, М.В. Маслова [и др.]; заявитель и патентообладатель Ин-т химии и технологии редких элементов и минер. сырья КНЦ РАН. - № 2011127614 ; заявл. 05.07.2011; опубл. 27.11.2012. Бюл. № 33 .

3. Мельников Д.В. Соликамский магниевый завод - стартовая площадка инноваций в россии / Д.Л. Мельников, А.В. Чуб, Д.В. Дробот // Вестник МИТХТ. 2013. Т. 8. № 3. С. 49-57.

4. Тюкавкина В.В. Получение аморфного кремнезема из шлаков цветной металлургии и его использование для магнезиальных вяжущих / В.В. Тюкавкина, А.Г. Касиков, Б.И. Гуревич, Е.А. Майорова // Химическая технология. 2014. № 3. С. 167-172.

5. Пат. 2625118 РФ, МПК С01G 23/00, С01B 33/32, С30В 29/34, В01J 20/10, 20/02, 20/30 (2006.01). Способ получения модифицированного титаносиликата фармакосидеритового типа / Н.Ю. Яничева, Я.Ю. Ганичева, А.Г. Касиков [и др.]; заявитель и патентообладатель Ин-т химии и технологии редких элементов и минер. сырья КНЦ РАН. № 2016121043/05; заявл. 27.05.2016; опубл. 11.07.2017. Бюл. № 20.

6. Яничева Н.Ю. Кристаллохимия обменных форм иванюкита / Н.Ю. Яничева, Т.Л. Паникоровский // Тр. Кольского научного центра. Химия и материаловедение. 2017. Вып. 1. С. 242-248.

7. Яничева Н.Ю. Синтез и применение титаносиликатных сорбентов группы иванюкита для очистки жидких радиоактивных отходов: автореф. дис. ... канд. техн. наук : 05.17.01 / Н.Ю. Яничева. Апатиты. Изд-во ФГБУН КНЦ РАН. 2017. 23 с.

8. Dadachov M.S. Synthesis and crystal structure of $\mathrm{Na}_{4} \mathrm{TiO}_{4}\left(\mathrm{SiO}_{4}\right)_{3} \cdot 6 \mathrm{H}_{2} \mathrm{O}$, a rhombohedrally distorted sodium titanium silicate pharmacosiderite analogue / M.S. Dadachov, W.T.A. Harrison // J. Solid State Chem. 1997. V. 134. P. 409-415.

9. Yakovenchuk V.N. Ivanyukite-Group Minerals: Crystal Structure and Cation-Exchange Properties / V.N. Yakovenchuk, E.A. Selivanova, S.V. Krivovichev [et al] // Minerals as Advanced Materials II ; edited by S.V. Krivovichev. - Berlin: Springer-Verlag Berlin Heidelberg, 2012. P. 205-211. 